\title{
UTILIZATION OF MACHINE LEARNING APPROACHES FOR TOOL WEAR DETECTION AND PREDICTION IN THE CIRCULAR SAWING PROCESS OF METALLIC MATERIALS
}

\author{
P. Georgi ${ }^{\star}, 1$, S. Eschelbacher, H.-C. Moehring ${ }^{1}$ \\ ${ }^{1}$ University of Stuttgart, Institute for Machine Tools, D-70174 Stuttgart, Germany \\ *Corresponding author; e-mail: patrick.georgi@ifw.uni-stuttgart.de
}

\begin{abstract}
Efficiency plays a major role in many areas of the mechanical processing of metals. Especially in basic provision of raw material, for example by cutting components to length during sawing, high penetration and thus efficiency as well as high robustness of the process is required. Here, the sawing tool and its durability is the decisive component in the process. In today's state of the art, at least in modern sawing machines, the condition is recorded via the sawing tool course or also via the motor current. This gives the operator an initial indication of the tool condition. In current machines an extensive sensory recording for e.g., accelerations as a characteristic for the tool condition is not used. The aim of the investigations described in the paper was to use measurement data from various internal and external sensors to record the state of the sawing tool wear and to analyse it using machine learning approaches. For this purpose, cutting tests were carried out on a modern sawing centre and the acquired measurement data were analysed using a convolutional neural network (CNN). During the tests, the internal and external sensors were compared to show which of the sensors used provides the best results in detecting wear on sawing tools. The investigations show that the CNN is suitable for detecting tool wear by means of the sensors used, which can be used for on-line monitoring. Finally, an outlook is given, and it is shown how the CNN can be used for active control in the sawing process.
\end{abstract}

\section{Keywords:}

Machine learning; circular sawing; tool wear detection

\section{INTRODUCTION}

The mechanical manufacturing landscape prevalent today makes process monitoring systems indispensable for ensuring process reliability as well as efficient and economical manufacturing systems [Denkena 2016]. The ever-increasing demand for process-monitored production equipment in machining is primarily due to the desire to maintain the required product quality in the face of increased product diversity [Denkena 2014]. Especially in basic provision of raw material, for example by cutting components to length during sawing, high penetration and thus efficiency as well as high robustness of the process is required. Here, the sawing tool and its durability is the decisive component in the process. The first approaches to process monitoring in the field of circular sawing were developed in the early 1990s. For the realisation of process monitoring, data from machine-internal process monitoring systems or from external signal sources are generated in the literature mentioned [Maulhardt 1991, Zaeh 1995]. One of the biggest problems is the development of suitable algorithms for feature selection [Denkena 2016]. The difficulty in process monitoring is that the process behaviour of the individual manufacturing systems is often non-linear and dynamic, with the relationships between input and output process variables being unknown or only partially known [Sick 2000, Toenshoff 1988]. This means that for supposedly identical machining conditions the results can be different which is why the behaviour of mechanical manufacturing processes is often described as chaotic [Pritschow 2004]. Therefore, in this scientific paper, a machine learning approach is described that detects tool wear in the circular sawing process of metal materials and thus further increases the efficiency of the process [Weiland 2018, Tandler 2021]. How and with which algorithms and techniques the data described here can be used to develop a self-optimising process is described in [Moehring 2020].

\section{Machine learning approaches for tool wear detection}

In the field of machine learning, simple mathematical models are often used to classify data sets or to perform regressions [Aunkofer 2018]. Current models are e.g., the K-nearest-neighbour model (KNN model) in which neighbouring data points are considered in multidimensional coordinates or support vector machines (SVM) based on geometric relationships. The detection of tool wear and defects is a wide field of research and there are numerous studies on this 
topic. Successful approaches exist, for example, using vibration and acceleration signals in conjunction with an and artificial intelligence approaches [Morales-Menndez 2008]. Lamraoui et al. realise the detection of surface properties as independently as possible from the process parameters with a piezoelectric sensor and a convolutional neural network (CNN). One sensor is attached to the clamping device, two others are attached to the tool holder [Lamraoui 2015]. Tatar et al. use a non-contact laser vibration measurement to detect vibrations, analysing the raw signal as well as the spectrum to detect tool wear [Tatar 2008]. Zhang et al. also estimate machine parameters to detect wear on the tool by updating an SVM via a Kalman-filtered input, they achieve a minimum error rate of less than three percent [Zhang 2014]. Kothuru et al. choose acoustic signals to detect wear on the tool [Kothuru 2018]. Sorgato et al. measure up to 50 percent surface degradation in combination with tool wear [Sorgato 2020]. Kim et al. list several studies that evaluate machine learning approaches in the field of milling. The studies listed relate to different objectives, including the detection of tool wear and deformations. The implemented approaches all achieve over 80 percent accuracy, despite quite different input data [Kim 2018]. In some cases, machine parameters are used, but also vibration signals. Some approaches achieve particularly good results with over 95 percent accuracy. In particular, the study by Krishnakumar et al. should be mentioned. An acceleration sensor attached to the spindle is used to estimate the tool condition. The acceleration signals are processed by an FFT analyser. With an artificial neural network (ANN), they achieve 95 percent in tool wear detection [Krishnakumar 2015]. In addition to acceleration signals, Khorasani also use machine parameters as input for an ANN. They thus achieve an accuracy of over 99 percent [Khorasani 2017].

In the following paper, the common approaches were compared in an evaluation matrix, see tab 1. The CNN approach was chosen, which is described in the following and examined based on machining tests.

Tab. 1: Approaches to the use of artificial intelligence in machining.

\begin{tabular}{lcccc}
\hline Properties & KNN & SVM & ANN & CNN \\
\hline $\begin{array}{l}\text { Generalisation } \\
\text { capability }\end{array}$ & 0 & 0 & + & + \\
$\begin{array}{l}\text { Automatic feature } \\
\text { extraction }\end{array}$ & - & - & 0 & + \\
$\begin{array}{l}\text { Application } \\
\text { performance }\end{array}$ & - & 0 & + & + \\
$\begin{array}{l}\text { Complexity of the } \\
\text { model }\end{array}$ & + & + & 0 & 0 \\
$\begin{array}{l}\text { Model training } \\
\text { effort }\end{array}$ & + & + & - & - \\
$\begin{array}{l}\text { Feature } \\
\text { extensibility }\end{array}$ & - & - & + & + \\
$\begin{array}{l}\text { Consideration of } \\
\text { features in the fre- } \\
\text { quency range }\end{array}$ & 0 & 0 & 0 & + \\
$\begin{array}{l}\text { Data preparation } \\
\text { scope }\end{array}$ & - & - & - & + \\
\hline \begin{tabular}{l} 
Overall valuation \\
\hline
\end{tabular} & - & 0 & 0 & + \\
\hline
\end{tabular}

\section{METHODOLOGY FOR THE SAWING PROCESS ANALYSIS USING MACHINE LEARNING}

\subsection{Experimental cutting tests}

\section{Experimental machine and kinematics}

The machine used in the tests is a near-series circular saw centre of the company KASTO Maschinenbau GmbH \& Co. KG. In addition to an automatic material feed system, it is equipped with a bar feeder for the storage of different profiles, diameters, and materials. Fig. 1 shows the three-dimensional external view of the experimental machine KASTOvariospeed C15.

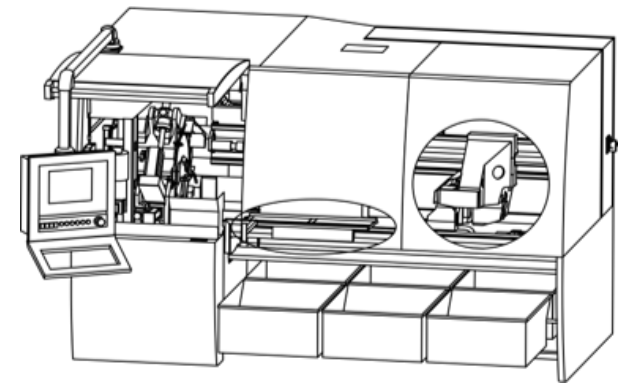

Fig. 1: Circular saw centre Kasto C15 [KASTO 2016].

The machine is designed as swivel arm kinematics, shown in fig. 2. The feed of the machine is arc-shaped in the $y$ direction. However, due to the size ratio of the workpiece to the tool, the feed can be considered almost linear. This simplification can be confirmed by looking at the motor current signals in the later part of the paper, see section 2.3.

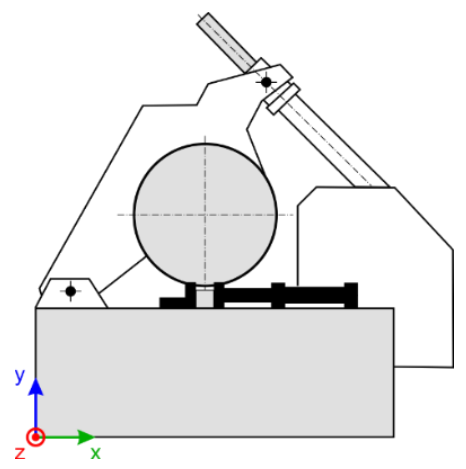

Fig. 2: Circular saw machine kinematics [Georgi 2018].

\section{Applied sensor technology}

Fig. 3 shows the mounted sawing tool, marked with 1 and the acceleration sensor marked with 2 . The accelerometer is a 3-axis MEMS sensor ADXL372 from Analog Devices Inc. The measurement range is $\pm 200 \mathrm{~g}$ with a bandwidth of $200 \mathrm{~Hz}$ to $3.2 \mathrm{kHz}$. The motor current and the blade path of the sawing tool are taken directly from the switch cabinet of the machine. The tool blade path is recorded by means of an eddy current sensor, which is installed as standard by the manufacturer of the circular saw machine. Furthermore, fig. 3 shows the schematic structure of the measurement data acquisition including the microcontroller.
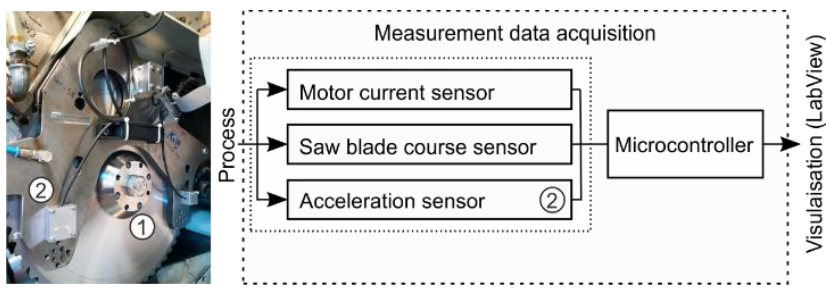

Fig. 3: Experimental setup [Georgi 2018]. 
Mathematical fundamentals in the circular sawing process

Fig. 4 shows the circular sawing process and its parameters. $d_{K}$ represents the diameter of the circular saw tool. For the experiments, the diameter $d_{K}$ is $425 \mathrm{~mm}$ with 60 teeth on the circumference. The tooth width is $2.7 \mathrm{~mm}$, which is equal to the cutting width $a_{p}$. The test sample has a diameter $d$ of $50 \mathrm{~mm}$ and consists of the material $42 \mathrm{CrMo} 4$ (1.7225). This results in the cutting parameters listed in tab. 2 , cutting speed of $v_{C} 100 \mathrm{~m} / \mathrm{min}$ and feed per tooth $f_{z}$ of $0.07 \mathrm{~mm}$. The pitch $T$ indicates the distance between two cutting edges. It is calculated by dividing the circumference of the circular saw blade by the number of teeth $z$. In addition to the pitch $T$, the pitch angle $\tau$ can be calculated. Here, the total angle of the circular saw blade is divided by the number of teeth $z$ of the circular saw blade. The maximum cutting angle $\varphi_{(d)}$ depends on the workpiece diameter $d$ and the circular saw blade diameter $d_{K}$ and can be calculated according to eq. 1 .

$\varphi_{(d)}=2 * \arcsin \left(\frac{d}{d_{k}}\right)$

The maximum cutting path $l_{\text {max }}$ can in turn be determined by the relationship between the cutting angle and the circumference of the circular saw blade. The cutting angle $\varphi_{(d)}$ and the pitch angle $\tau$ can be used to determine the teeth $z_{e}(\varphi)$ that are in cutting engagement during machining, see eq. 2 [Tschaetsch 2007].

$z_{e(\varphi)}=\frac{\varphi_{(d)}}{\tau}$

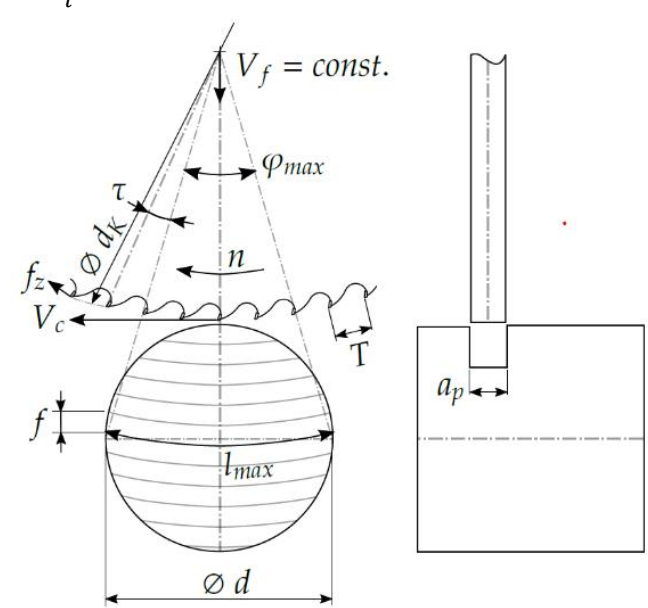

Fig. 4: Characteristics in the circular sawing process [Georgi 2018].

Finally, the cutting force $F_{C(\varphi)}$ and the cutting power $P_{C(\varphi)}$ can be calculated via eq. 3 or eq. 4 . In addition to the teeth in mesh determined in eq. 2 , the tooth feed $f_{Z}$, the rise value $1-z$ and the specific cutting force $k_{c 1.1}$, the process factor $k_{S}$ and the wear correction $k_{T}$ are used.

$$
\begin{aligned}
& F_{C(\varphi)}=a_{p} * f_{z}^{1-z} * z_{e(\varphi)} * k_{c 1.1} * k_{s} * k_{T} \\
& P_{c(\varphi)}=F_{c} * V_{c}
\end{aligned}
$$

\section{Parameters of the machining tests}

To keep the scope of the tests small, one combination of machine parameters is used initially. The machine parameters investigated in the tests are the cutting speed $v_{C}$ and the feed per tooth $f_{z}$. Furthermore, four identical tools with different degrees of wear are used. For static hedging, each test parameter is repeated 15 times. The test parameters can be gathered from tab. 2 .
Tab. 2: Experimental parameters.

\begin{tabular}{cccc}
\hline $\begin{array}{c}\text { Number } \\
\text { of cuts } \\
n_{C}\end{array}$ & $\begin{array}{c}\text { Number } \\
\text { of tools }\end{array}$ & $\begin{array}{c}\text { Cutting speed } \\
n_{T}\end{array}$ & $\begin{array}{c}v_{C} \\
{[\mathrm{~m} / \mathrm{min}]}\end{array}$ \\
\hline-$]$ & {$[-]$} & 100 & $\begin{array}{c}f_{Z} \\
{[\mathrm{~mm}]}\end{array}$ \\
\hline 15 & 4 & 0.07 \\
\hline
\end{tabular}

\subsection{Classification of the tool wear}

Fig. 5 shows the characterisation of the tool wear as well as the angels of the tool teeth. One possible cause of wear is abrasion of the tool because of sliding between the tool and the workpiece by hard components of the workpiece material. The abrasion is supported by high surface temperatures on the rake and flank and the associated softening of the cutting material and is used as a characteristic value in this paper in the form of the wear mark width $V B$ [Denkena 2010, Liebrecht 1990]. Figure 5a shows the unused tool. Figure $5 \mathrm{c}$ to $5 \mathrm{e}$ shows the wear progression from tool 2 to tool 4. The recorded wear characteristics are shown in Table 3. Figure $5 \mathrm{~b}$ shows the angles on the saw tooth. The clearance angle $\alpha$ is 5 degrees. The wedge angle $\beta$ is 110 degrees. The rake angle $\gamma$ is a negative rake angle of -25 degrees.

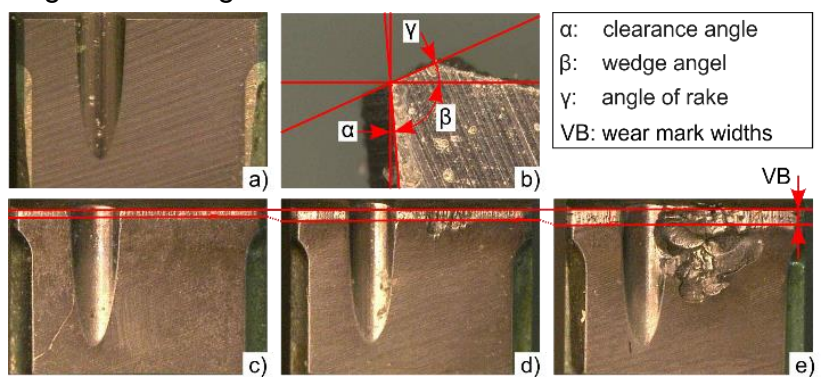

Fig. 5: Tool characteristics and wear criteria [Georgi 2018].

Another characteristic value used in the paper is the area performance of the tool $F L$, i.e., the cross-section of the workpiece already machined by the tool. Both characteristic values for the tools used in the tests can be taken from tab. 3.

Tab. 3: Tool wear characteristics.

\begin{tabular}{ccc}
\hline Tool Nr. & Area performance & Wear mark width \\
$n_{T}$ & $F L$ & $V B$ \\
{$[-]$} & {$\left[\mathrm{m}^{2}\right]$} & {$[\mu \mathrm{m}]$} \\
\hline 1 & 0.00 & 0.00 \\
2 & 6.80 & 79.56 \\
3 & 13.00 & 112.03 \\
4 & 24.00 & 173.95 \\
\hline
\end{tabular}

\subsection{Development of the sensor values}

The sensor characteristics defined for the algorithm development are described below.

\section{Acceleration}

To develop a corresponding characteristic value for the sensor data recorded by the 3-axis acceleration sensor, the signal was first observed in time domain. After no corresponding significant feature could be detected in the time signal, see fig. 6a, the time signal was transformed into the frequency domain using Fast Fourier Transformation (FFT), see fig. $6 \mathrm{~b}$. As Figure $6 \mathrm{~b}$ shows, the first significant peak in the frequency domain was selected as the characteristic. 
This value represents a multiple of the tooth meshing frequency. The maximum peak height of this characteristic is used as a characteristic value for the machine learning approach.

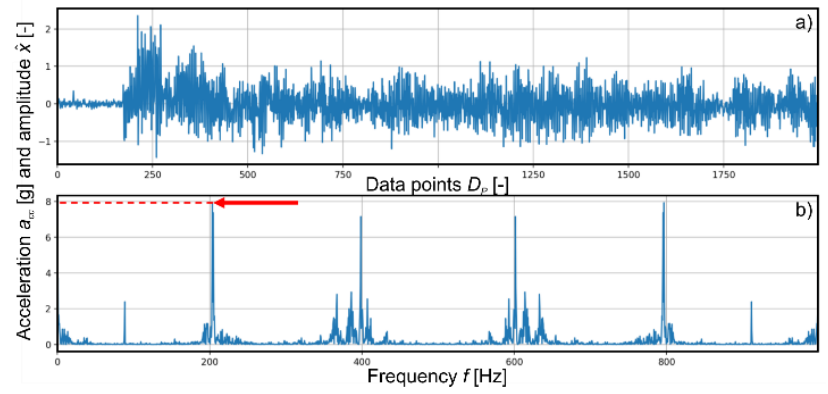

Fig. 6: Characteristic value definition of the acceleration signal.

\section{Sawing tool course}

For the definition of a further characteristic value as input of the machine learning algorithm, the signal of the eddy current sensor of the machine manufacturer is used. The signal of the sawing tool course is considered in the time domain. As fig. 7 shows, the sawing tool course changes depending on the tool wear condition. The rise angle of the sawing tool course can therefore be used as a characteristic value for the machine learning approach as a wear-related feature. A negative gradient is possible and represents the new tool in the example shown in fig. 7 .

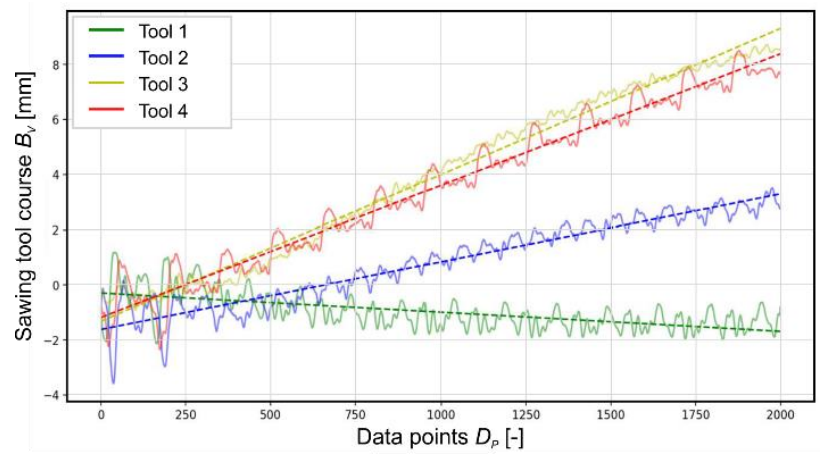

Fig. 7: Characteristic value definition of the sawing tool course signal.

\section{Motor current}

The last input parameter for the machine learning algorithm is the motor current during machining, see fig. 8 . Here, the energy and thus the area under the signal curve of the motor current sensor is used as a characteristic for the wearrelated change. The motor current signal provided the best result compared to the two other parameters (acceleration signal, sawing tool course) defined.

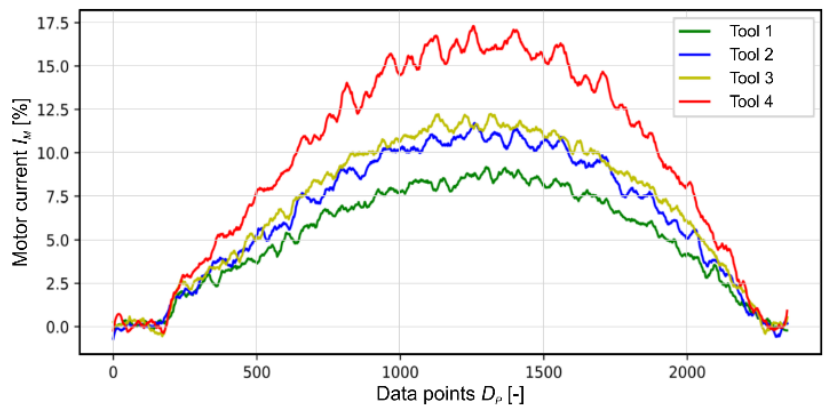

Fig. 8: Characteristic value definition of the motor current signal.

\subsection{Structure of the machine learning approach}

Fig. 9 shows the machine learning scheme developed in the experiments. The CNN was developed in Python and Kreas was used as the freeware for the training. SoftMax is used as the activation function in the output level since it is a classification with several classes. The SoftMax function outputs a probability of class membership for each class in the output vector and tries to best approximate the actual class. It ensures that the sum of the probabilities over the output vector is 1 . The deviation between the actual and predicted probability distribution is calculated using the cross-entropy function and then used to update the model. The data set is split in a ratio of $60 \%$ training samples to $40 \%$ test samples.

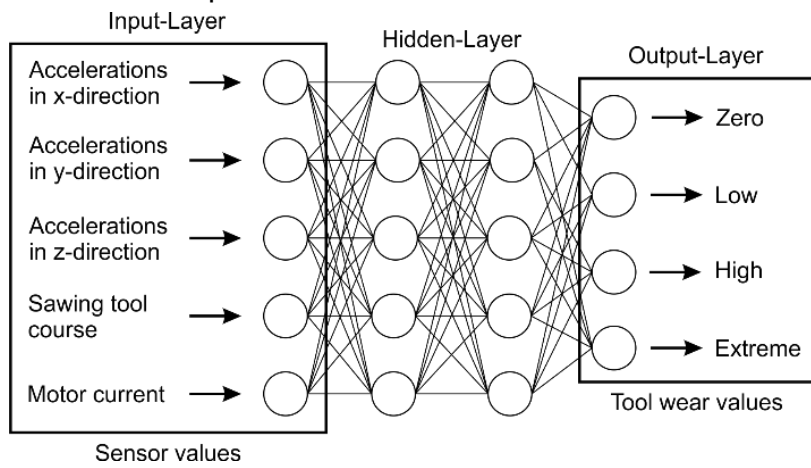

Fig. 9: Convolutional neural network.

\section{EXPERIMENTAL RESULTS}

\subsection{Loss}

The loss value is a sign of quality. It indicates convergence, overfitting and underfitting. High loss values indicate a poorly fitted network. It should be noted that the loss values are only an abstract measure. For the loss value, the crossentropy loss function seen in eq. 5 is used to calculate the logarithmic deviation between actual and estimated class. In eq. $5, a$ is set to a low value so that the logarithm does not run into the infimum and the computing times of the network does not increase significantly.

Loss $=\frac{\left.\sum_{i} y_{i} * \log \left(a+\hat{y}_{i}\right)\right)}{i}$

Fig. 10 shows the results of the loss values for the CNN used. The loss value for the developed motor current characteristic shows a good result.

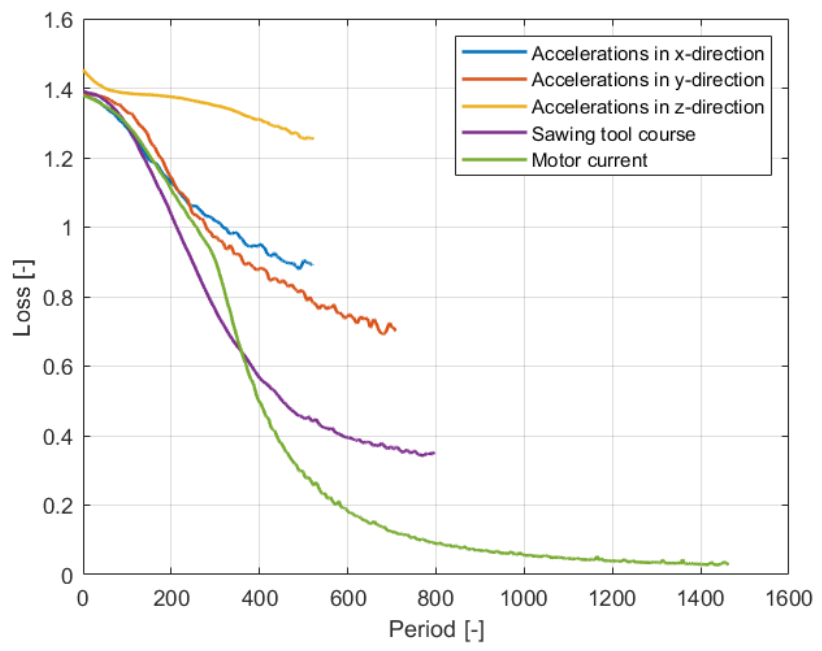

Fig. 10: Loss of the CNN algorithm. 
The loss value approaches the abscissa of the diagram asymptotically after about 1500 interactions in the CNN algorithm. The defined characteristic value for the sawing tool course also shows an acceptable result. The loss value of the sawing tool course characteristic value no longer changes after approx. 800 iterations. With the acceleration characteristic values, only the $y$-direction of the sensor signal and the feed direction of the saw blade provide an acceptable result. The loss value no longer changes from about 700 iterations of the CNN algorithm.

\subsection{Accuracy}

The accuracy can be used as a further characteristic value for the quality of the CNN. The accuracy function is introduced that tolerates a deviation of up to 0.2 , where diff $f_{\max }$ is defined as the maximum accepted deviation. The function is shown in eq. 6 - 7. The deviations are averaged over all classes. This accuracy function does not consider weak classifications. For the actual class at least 0.8 , for the rest a maximum of 0.2 must be reached to be considered as a successful classification.

$$
\begin{aligned}
& \operatorname{diff}_{\text {max }}=|y-\hat{y}| \\
& \text { accuracy }=\frac{\sum_{i}\left\{\begin{array}{l}
1, \text { if }\left(\operatorname{diff}_{i}<\operatorname{diff} f_{\text {max }}\right) \\
0, \text { if }\left(\operatorname{diff} f_{i}>\operatorname{diff} f_{\text {max }}\right)
\end{array}\right.}{i}
\end{aligned}
$$

For a further impression of the accuracy of the CNN, a second approach is used to determine it. The accuracy is determined by the strongest class, where max index determines the index of the maximum value. This accuracy determination does not consider the weighting of the individual classes. It is referenced as the classification accuracy and is shown in eq. 8 . The results for the network used for the tests are shown in fig. 10 and fig. 11.

$$
\operatorname{accuracy}_{\text {class }}=\left\{\begin{array}{c}
\left.1, \text { if } \max _{\text {index }}(\hat{y})=\max _{\text {index }}(y)\right) \\
0, \text { else }
\end{array}\right.
$$

Fig. 11 shows the accuracy achieved by the CNN in the characterisation of the corresponding wear for each sensor signal. The wear condition of the circular saw tool can be detected very well and with almost $100 \%$ via the motor current characteristic value. Furthermore, fig. 11 shows that by means of the extracted sawing tool course characteristic value, the wear condition of the sawing tool was correctly predicted by about $88 \%$. The acceleration characteristic value in the $y$-direction also showed a good result in the correct prediction of the tool wear condition. It is about $80 \%$ for the acceleration characteristic value in the $y$-direction. The other acceleration values in $z$ - and $x$-direction do not show a clear result. The accuracy is about $70 \%$ in the $x$ direction and $62 \%$ in the z-direction.

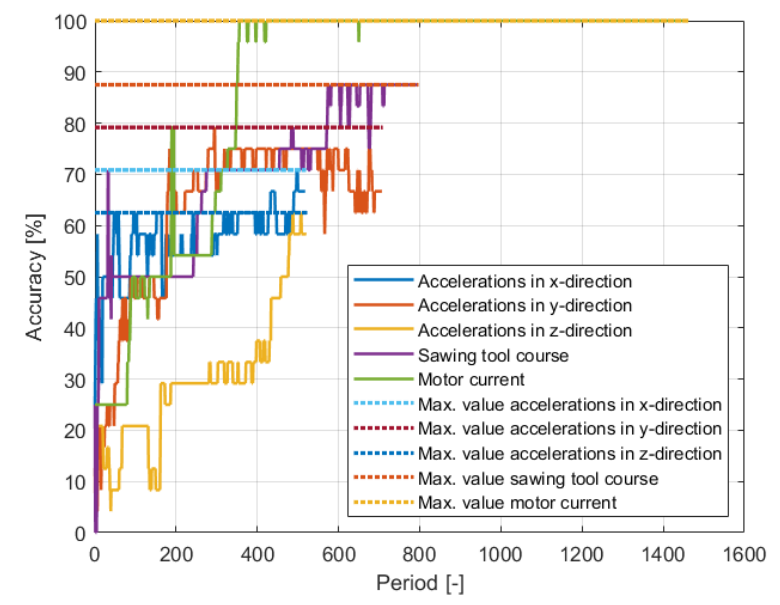

Fig. 11: Accuracy of the CNN algorithm.

\section{CONCLUSION AND OUTLOOK}

In this paper, a corresponding machine learning algorithm was developed using internal and external machine sensors and was tested based on machining experiments. The developed machine learning algorithm is a convolutional neural network CNN with five input values and four output values as well as two hidden layers. Five sensor signals were examined for the input values and a corresponding sensor characteristic value was developed for each. For the output values, the wear condition of four identical circular sawing tools was considered. In addition to the area performance value $F L$, the wear mark width $V B$ was used. The wear was divided into four areas: zero, low, high and extreme. Using the developed input and output parameters, the CNN was first trained and then verified using independent measurement data. As shown in Fig. 12, it was possible to demonstrate that the sensor parameters extracted can identify the wear on the sawing tool used to varying degrees.

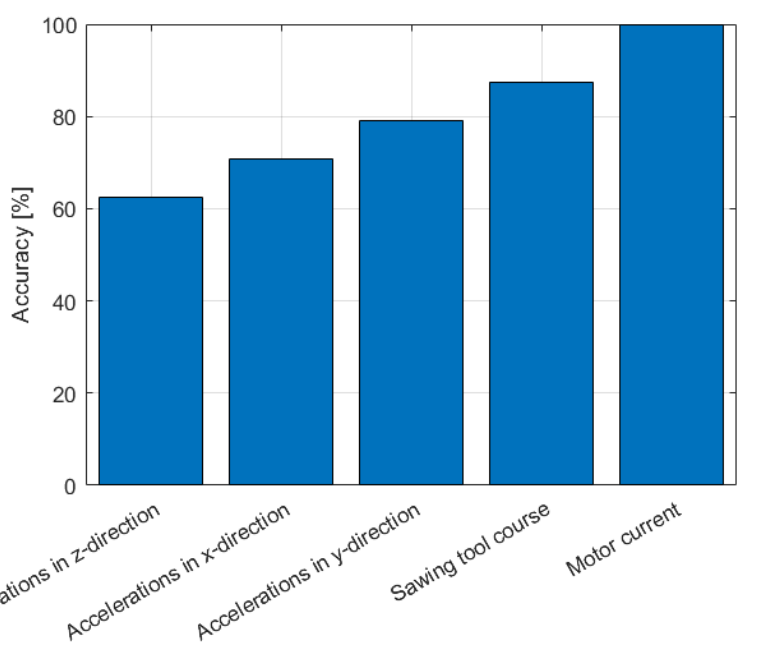

Fig. 12: Accuracy of the CNN algorithm.

The MEMS acceleration sensor used performed most unpalatable in the detection of tool wear. Especially in $\mathrm{x}$ - and $z$-direction the accuracy was $60-70 \%$. In the feed direction, y-direction, the wear condition could be detected with about $80 \%$ accuracy. The sawing tool course signal used showed an accuracy of $88 \%$. The most significant result in the tests was the motor current characteristic value. The achieved accuracy for the motor current characteristic value was close to $100 \%$.

To verify and further modify the algorithm, it is planned to investigate further parameter variations. In addition to the machine parameters, cutting speed $v_{C}$ and the feed per tooth $f_{z}$, other materials and workpiece profiles as well as tools are to be considered to use the developed algorithm for series machining of components. Furthermore, the CNN will be used to design an adaptive control system that varies the described machine parameters in such a way that the circular sawing process can be designed more economically. In this case, this means lower tool consumption due to higher utilization of the tools, e.g. higher cutting speeds, but also longer use due to the sensory observation of the service life cycle. 


\section{REFERENCES}

[Denkena 2016] Denkena, B. et al.: Prozessueberwachung in der Zerspanung. In: ZWF - Zeitschrift für wirtschaftlichen Fabrikbetrieb 111, 2016, Nr. 4, P. 174-177.

[Denkena 2014] Denkena, B. et al.: Industrie 4.0 in der Zerspanung. In: ZWF - Zeitschrift für wirtschaftlichen Fabrikbetrieb 109 2014, Nr. 7-8, P. 537-541.

[Zaeh 1995] Zaeh, M. F.: Dynamisches Prossmodell Kreissaegen: Disseration. Berlin, Heidelberg, New York: Springer, 1995.

[Maulhardt 1991] Maulhardt, U.: Dynamisches Verhalten von Kreissaegen: Disseration. Bd. 38. Berlin, Heidelberg, New York: Springer, 1991.

[Sick 2000] Sick, B.: Signalinterpretation mit Neuronalen Netzen unter Nutzung von modellbasierten Nebenwissen am Beispiel der Verschleißueberwachung von Werkzeugen in CNC Drehmaschinen: Disseration. Duesseldorf: VDI Verlag, 2000.

[Toenshoff 1988] Toenshoff, H. K. et al.: Developments and Trends in Monitoring and Control of Machining Processes. In: CIRP Annals - Manufacturing Technology 37 (1988), Nr. 2, S. 611-622.

[Pritschow 2004] Pritschow (Hrsg.), G.: Autonome Produktion. Berlin, Heidelberg: Springer-Verlag, 2004.

[Moehring 2020] Moehring, H.-C. et al.: Self-optimizing machining systems. CIRP Annals - Manufacturing Technology 69 (2020) 740-763

[Weiland 2018] - Weiland, S. et al.: A pragmatic approach to high speed circular sawing. 14th International Conference High Speed Machining, San-Sebastian, Spain, 17.18. April 2018

[Tandler 2021] - Tandler, T. et al.: Effekt der Saegekinematik auf die Prozesseffizienz. Wt Werkstattstechnik, Band 111 (2021) Nr.1-2:2-7

[Aunkofer 2018] Aunkofer B.: Machine Learning vs Deep Learning - Wo liegt der Unterschied? Data-ScienceBlog.com https://data-science-blog.com/blog/ 2018/05/14/ machine-learning-vs-deep-learning-wo-liegt-der-unterschied/ 2018.

[Morales-Menndez 2008] J., A.; Morales-Menndez, R.; Alique, J. R.: On-line Cutting Tool Condition Monitoring in Machining Processes Using Artificial Intelligence. In: Pecherkova, P. et al. (Hrsg.): Robotics Automation and Control 2008.

[Lamraoui 2015] Lamraoui, M. et al.: Chatter detection in milling machines by neural network classification and feature selection. In: Journal of Vibration and Control 21 (2015) 7, P. 1251-1266.
[Tatar 2008] Tatar, K.; Gren, P.: Measurement of milling tool vibrations during cutting using laser vibrometry. In: International Journal of Machine Tools and Manufacture 48 (2008) 3-4, P. 380-387.

[Zhang 2014] Zhang, $\mathrm{H}$ et al.: Tool wear model based on least squares support vector machines and Kalman filter. In: Production Engineering 8 (2014) 1-2, P. 101-109.

[Kothuru 2018] Kothuru, A. et al.: Application of audible sound signals for tool wear monitoring using machine learning techniques in end milling. In: The International Journal of Advanced Manufacturing Technology 95 (2018) 9-12, P. 797-808.

[Sorgato 2020] Sorgato, M. et al.: On the correlation between surface quality and tool wear in micro-milling of pure copper. In: Journal of Manufacturing Processes (2020) 50.

[Kim 2018] Kim, D.-H. et al.: Smart Machining Process Using Machine Learning: A Review and Perspective on Machining Industry. In: International Journal of Precision Engineering and Manufacturing-Green Technology 5 (2018) 4, P. 555-568.

[Krishnakumar 2015] Krishnakumar, P. et al.: Tool Wear Condition Prediction Using Vibration Signals in High-Speed Machining (HSM) of Titanium (Ti-6Al-4V) Alloy. In: Procedia Computer Science 50 (2015), P. 270-275.

[Khorasani 2017] Khorasani, A.; Yazdi, M. R. S.: Development of a dynamic surface roughness monitoring system based on artificial neural networks (ANN) in milling operation. In: The International Journal of Advanced Manufacturing Technology 93 (2017) 1-4, P. 141-151.

[KASTO 2014] KASTO Maschinenbau GmbH \& Co. KG: Bedienungsanleitung KASTOvariospeed C15. Achern, 2014.

[Georgi 2018] Georgi, P.: Parameter study for the detection of contexts in circular saw process data by internal and external machine data. Masterarbeit, Institut für Werkzeugmaschinen, Universitaet Stuttgart, 2018.

[Tschaetsch 2007] Tschaetsch, H.: Applied Machining Technology. Springer, Berlin, Heidelberg, ISBN 978-3-64201006-4, 2007.

[Denkena 2010] Berend D.: Spanen Grundlagen. SpringerVerlag, Berlin, Heidelberg, ISBN 978-3-642-19771-0, 3 edition, 2010.

[Liebrecht 1990] Liebrecht, R.: Verringerung von Werkzeugfehlern, Schnittverlust und Geraeuchen beim Sägen mit Kreissaegeblaettern: Dissertation, volume 199 of Fortschritt-Bericht VDI. VDI-Verlag GmbH, Düsseldorf, ISBN 318-149902-1, 1990. 